\section{REFLEXÕES DE EDGAR MORIN, PIAGET E ATLAN A RESPEITO DO CONCEITO DE COMPLEXIDADE}

Autor (a):

Erlane Paes de L. Silva

Co-autor (a) (s):

Adriana Bizarria da Silva; Leidjane Barbosa Azevedo

Orientador (a):

Prof ${ }^{a}$ Dra Maria Betânia Moreira Amador

Instituição:

UPE - Campus Garanhuns

E-mail:

leid-azevedo@hotmail.com

Palavras chave:

Complexidade. Educação ambiental. Geografia.

\section{INTRODUÇÃO}

Edgar Morin considerado por muitos como o pai da complexidade, na qual defende a interação dos conhecimentos em seus estudos, também introduziu o cultural nas ciências naturais e o natural nas antropo-cultural. $O$ objetivo dele era alcançar a reforma do pensamento teórico e conceitual, a fim de incorporar nas ciências do homem o conceito de vida. Ele observou que quanto mais autônomo mais surge a complexidade do meio ambiente 
salientando que, de fato, sempre ocorrerá uma inter-relação sobre o qual dirigimos os nossos olhares. A complexidade indica que tudo se liga a tudo e, reciprocamente, numa rede relacional e interdependente, ressaltando que a idéia de que nada está isolado no cosmos, mas sempre em relação à algum elemento. Observa-se, ainda que, ao mesmo tempo em que o individuo é autônomo, é também dependente, numa circularidade que o singulariza e distingue simultaneamente.

Morin, Piaget e Atlan definiram muito bem o caráter organizacional desse paradoxo: a organização é um complexo de variedades e de ordem repetitiva (redundância); pode ser considerado um compromisso ou uma conjugação entre o Máximo de variedade e o Máximo de redundância. Nessa vertente analítica, a primeira e fundamental complexidade do sistema é associar em si a idéia de unidade, por um lado, e de diversidade ou multiplicidade por outro. As quais, a princípio, se repelem e se excluem. Pode-se dizer que a idéia de unidade complexa ganhará densidade se pressentirmos que não podemos reduzir o todo ás partes nem as partes ao todo.

De fato, a idéia de uma espiral da eco-organizaçao transporta a cadeia trófica e indica que não somente uma reorganização permanente responde a desorganização permanente, mas, sobretudo, que o processo de organização está no próprio processo de desorganização.

A ecologia dos sistemas complexos é, antes de tudo, a consideração dos processos atuantes num espiral trófico, composto de subsistemas (também complexos) em interação. São nessas entidades de interações que o crescimento da complexidade comporta, correlativamente, crescimento da ordem, da desordem e da organização. Um desenvolvimento da complexidade não é, necessariamente, um aumento quantitativo de diversidade, e o desenvolvimento de diversidades obedece, por sua vez, a princípios complexos, isto é, não apenas quantitativos. Nesse processo dialético é preciso saber que, no esforço de uma construção de modelização de uma 


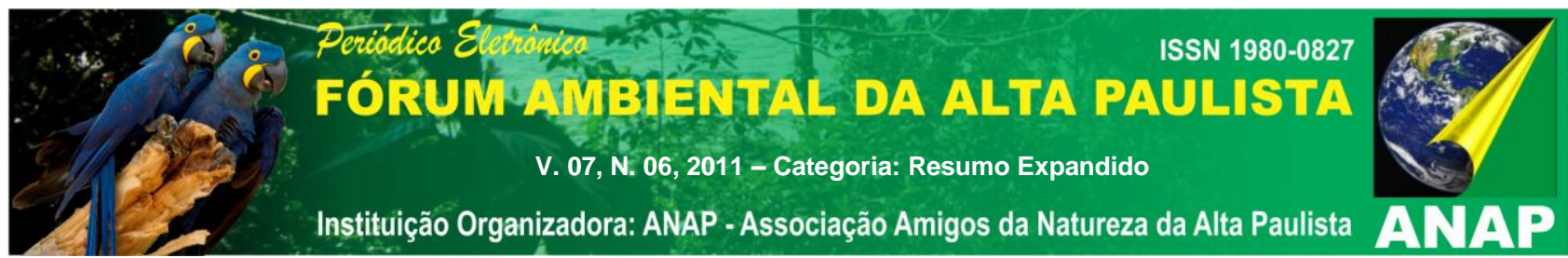

complexidade ecológica, deve-se considerar que "o homem esta na natureza; a natureza está no homem" (MORIN, 2003, 71).

\section{OBJETIVO GERAL}

Despertar o interesse pela leitura do tema complexidade e sua aplicação no contexto geográfico e, especificamente na educação ambiental.

\section{OBJETIVOS ESPECÍFICOS}

Perceber a visão sistêmica, a partir da leitura de obras que tratem da complexidade.

Associar a possibilidade de atuar na educação com maior inter/multi e transdisciplinaridade.

Admitir a subjetividade do conhecimento próprio como elemento importante no âmbito da educação ambiental.

Estimular, na medida do possível, pesquisas de TCC na linha sistêmica.

\section{METODOLOGIA}

Recorreu-se ao trabalho bibliográfico sobre obras de ordem ecológica, com base moriniana acompanhadas de reflexões e discussões no âmbito do grupo de estudos e pesquisas GESSNE - Grupo de Estudos Sistêmicos do NordEste sob orientação da líder do grupo.

\section{RESULTADOS}




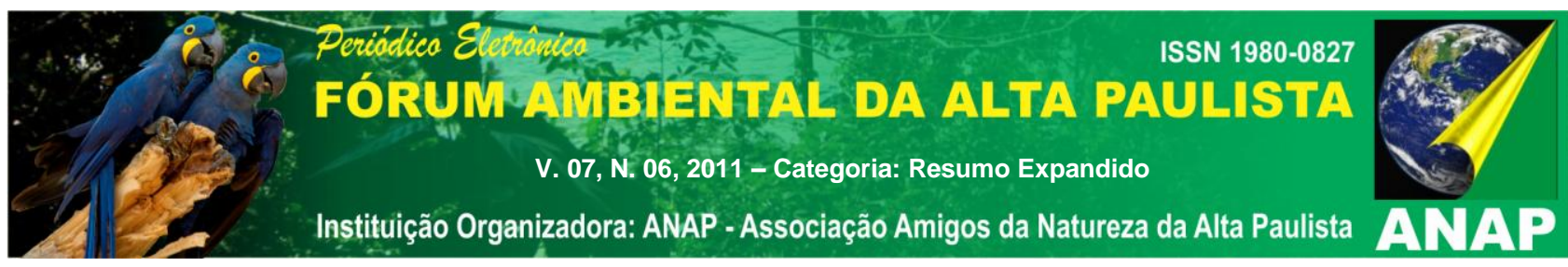

Até o momento houve significativo progresso, principalmente no que tange ao entendimento da concepção de complexidade, bem como motivação para seqüenciar mais leituras e esquematizar pesquisas no âmbito de trabalho da Licenciatura em Geografia contemplando, especificamente, a Educação Ambiental.

\section{CONSIDERAÇÕES FINAIS}

Considera-se oportuno socializar essa fase de pesquisa e estudos, pois captar novos horizontes além do tradicional positivismo da ciência e do dia a dia universitário, é crescer, amadurecer frente à dinâmica intelectual que permeia a vida acadêmica e social dos participantes do GESSANE.

\section{REFERÊNCIAS}

PENA-VEGA, Alfredo. O despertar ecológico: Edgar Morin e a ecologia complexa. Tradução de Renato Carvalheira do Nascimento e Elimar Pinheiro do nascimento. Rio de Janeiro: Garamond, 2003. 